\title{
NOVEL ADIPOCYTE FEATURES DISCOVERED BY ADIPOPROTEOMICS
}

\section{Johan Renes, Anja Rosenow, and Edwin Mariman}

Department of Human Biology, NUTRIM School for Nutrition, Toxicology and Metabolism, Maastricht University, Maastricht, The Netherlands

\section{Abstract}

Obesity and its associated complications will be the most important near-future medical burden in Western-type societies. One hallmark of obesity is the differentiation of preadipocytes into mature fat-loaded adipocytes present in subcutaneous and visceral fat depots. Furthermore, (pre)adipocytes secrete proteins, known as adipokines, with changing profiles during fat accumulation. Adipocytes serve in important function with respect to energy homeostasis, body insulation and organ protection. Adipocyte dysfunction results in the initiation and progression of obesity-associated disorders. Obviously, knowledge of the adipocyte behaviour under different nutritional conditions and the cross-talk of adipocytes with other cells and organs are key issues to develop proper intervention strategies. A full understanding of the adipocyte behaviour requires a systems biology approach with integrated transcriptomics, proteomics and metabolomics data. This review focuses on the contribution of proteomics research in adipocyte biology. Proteome studies on adipocytes exist for almost 30 years but are boosted in the last decade with the enormous technological developments in mass spectrometry technology. The relevance of proteomics technologies in understanding molecular aspects of adipocyte biology is discussed. Recent novel findings and particularly the identification of novel adipokines are highlighted.

Adipobiology 2009; 1: 7-18

Key words: adipobiology, adipokines, proteomics, 3T3-L1, human models

Received 20 July 2009, accepted 15 August 2009.

Correspondence and reprint request: Dr Johan Renes, Department of Human Biology, Maastricht University, P.0. box 616, 6200

MD, Maastricht, The Netherlands. Tel.: 31 (0) 43-3881 633, Fax: 31 (0) 43-3670 976, E-mail: j.renes@hb.unimaas.nl

\section{Introduction}

Adipocytes play an essential role in normal physiology with respect to energy balance, glucose homeostasis, heat regulation and organ protection. Furthermore, adipocytes are involved in the immune response, blood pressure control, haemostasis, bone mass, and thyroid and reproductive function $(1,2)$. A deregulation of the adipocyte function results in metabolic dysfunction of the body and the development of obesity-associated diseases like type 2 diabetes, non-alcoholic steatohepatitis, cardiovascular diseases and cancer $(3,4)$. With the expected increase in the global overweight population (WHO, Fact sheet on obesity and overweight, September 2006, http://www.who.int/topics/obesity/ en/), the number of people that suffer from obesity-associated diseases will consequently rise too (5-7). Understanding the molecular events leading to adipocyte dysfunction and the related metabolic complications is thus required to provide targets for appropriate intervention to reduce the upcoming metabolic disease burden. During the last decades genomics technologies provided further insights regarding the molecular events underlying the development of obesity and 
related diseases.

Here the contribution of proteomics research with respect to adipocyte biology is highlighted. It is beyond the scope of this review to describe each adipocyte protein that has been identified instead novel biological features of adipocytes discovered by proteomics are discussed.

\section{The proteome: more than just the protein complement of the genome}

The molecular events during preadipocyte differentiation have been examined in a broader sense by several large-scale gene analysis studies (8-10). Although transcriptomics data provide important information about transcription rates and mRNA turnover, knowledge about protein expression, post-translational modifications and protein turnover, essential for cellular physiology, cannot be covered by this technology. In addition, the correlation between mRNA expression levels and the expression levels of corresponding protein products is low in mammalian systems (11). For instance, we previously showed that insulin stimulated protein secretion from murine 3T3-L1 adipocytes without increasing the mRNA levels of the corresponding genes (12). Together, additional monitoring of the cellular protein complement, the proteome, is required to further understand the adipocyte behaviour. The importance of this issue is reflected by the overwhelming amount of different proteins that can be produced by a single genome due to alternative splicing and post-translational modifications. In contrast to the genome, the proteome is highly dynamic that differs in time and in response to external factors (13). Furthermore, expression and function of many proteins are modified through interactions with other proteins such as kinases and proteases. In fact, most biological systems are controlled by complex protein-protein interaction networks (14). Consequently, detailed proteome studies may provide additional valuable information about the (patho)physiology of an organism. The dynamic nature of the proteome can be a pitfall for reproducible results, as such, proteome studies require careful experimentation under well-defined conditions.

\section{Proteome analysis strategies}

It is currently not possible to analyse the total proteome of an organism at once. This is due to $(i)$ extreme complexity of the proteome, (ii) the dynamic nature of the proteome, (iii) limitations of the analysis techniques to cover the orders of magnitude difference in protein expression levels, and (iv) the differences in physical properties of the proteins. Three main strategies that are currently applied in large-scale proteome research are (i) gel-based protein separation, either by 1 - or 2-dimensional electrophoresis $(2-\mathrm{DE})$, combined with mass spectrometry $(15,16)$, (ii) liquid chromatography coupled to tandem mass spectrometry (LC-MSMS) (17,18), and (iii) antibody array technology $(19,20)$, see Figure 1.

\section{(Dis)advantages of current proteomics strategies}

The 2-DE method is a high-resolution technology enabling the simultaneous visualisation of many different proteins, including splice variants and proteins bearing post-translational modifications $(16,21)$. However, the sensitivity of the 2-DE technique is restricted to relatively high abundant proteins leaving large parts of the proteome obscure. Furthermore, the reproducibility of the 2-DE method heavily depends on experimental conditions. With the introduction of the differential gel electrophoresis (DIGE) technology qualitative and quantitative comparison of two different samples on a single gel became possible by prelabelling of the protein samples with different CyDyes $(22,23)$. This technology is an improvement compared to traditional 2-DE regarding reproducibility, quantitative proteome analyses and statistical confidence of differential protein expression. Still, hydrophobic (membrane) proteins, proteins with low $(<5 \mathrm{kD})$ or high $(>250 \mathrm{kD})$ molecular masses and extremely acidic $(\mathrm{pI}<$ 3 ) and basic ( $\mathrm{pI}>11)$ proteins are difficult to resolve with 2 -DE. Furthermore, many proteins identified among several different studies using 2-DE combined with Maldi-TOF MS appeared to be generally stress-related proteins (24). Considering these proteins as biomarkers for cellular processes other than a stress response should be done with great care. Additional validation studies are required to confirm their specificity.

The LC-MSMS approach is not hampered by the size of proteins and their hydrophobic properties. In combination with stable isotope labelling such as iTRAQ and SILAC LC-MSMS is highly suitable for accurate quantitative proteomics $(17,25)$. Compared to 2-DE, LC-MSMS is a more sensitive method able to cover larger ranges of the proteome and it can be run in an automated fashion (26-28). However, in contrast to 2-DE, LCMSMS cannot discriminate proteins and their splice variants as the identified peptides are assigned to the same protein. Reliable analysis of post-translational modifications, particularly phosphorylation and glycosylation, requires additional sample preparation due to similar reasons. Furthermore, the tremendous amount of data generated by current MSMS instruments has become a bottleneck in analysis time and requires extensive bioinformatics tools. Despite these limitations, the LC-MSMS technology is currently the most popular approach applied in proteome research.

The antibody array technology is a sensitive and reproducible method to quantitatively measure protein abundances in complex samples. It requires little amounts of sample and allows 

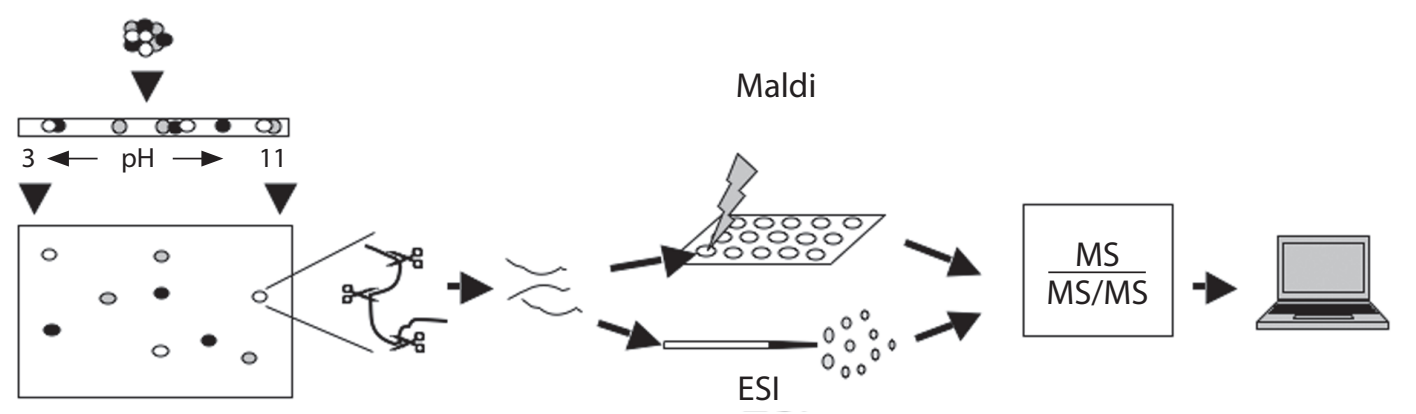

(i)

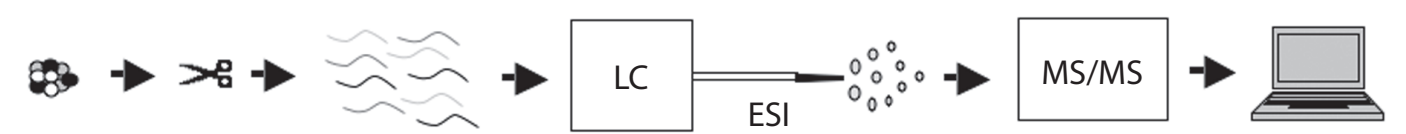

(ii)

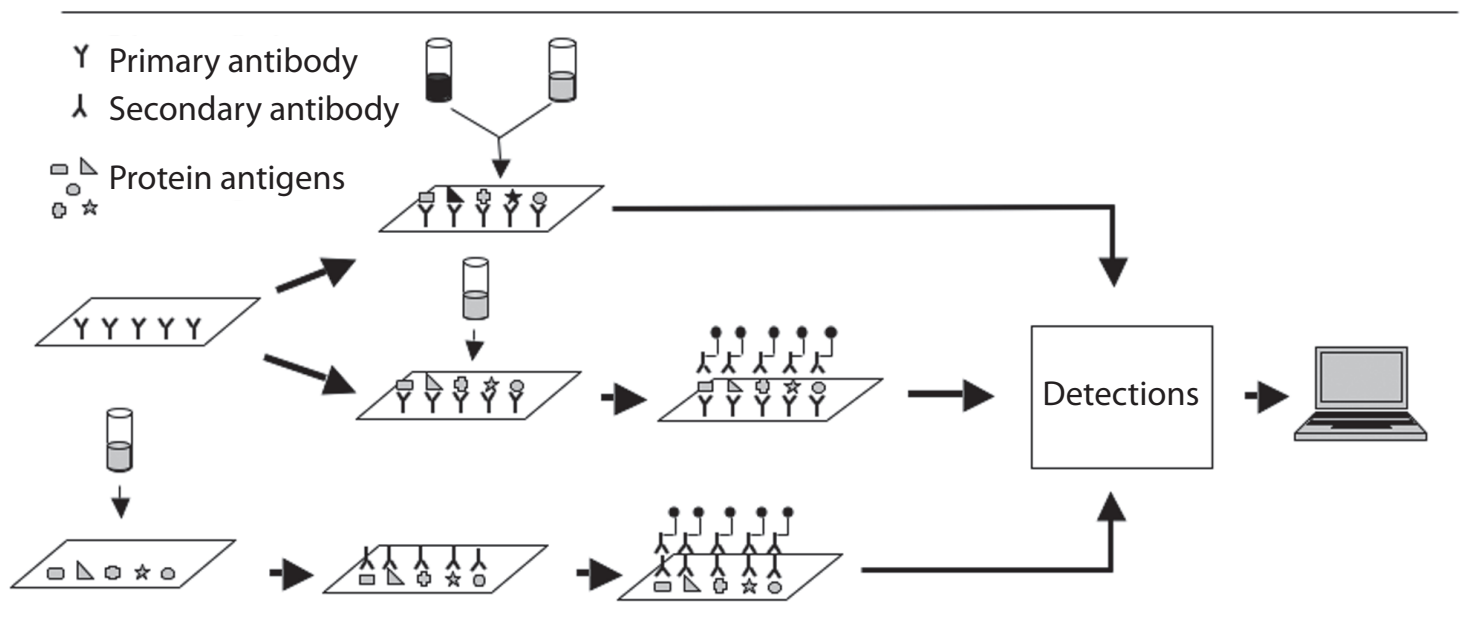

(iii)

Figure 1. Current strategies in large-scale proteomics studies.

(i) Proteomics by 2-DE combined with mass spectrometry. With 2-DE a protein sample is first separated by iso-electric focussing on an immobilized pH gradient (max. $\mathrm{pH} 3-11$ ) according to the iso-electric points of the proteins. Subsequent separation is based on the molecular mass of the proteins by using sodium dodecyl sulphate polyacrylamide gel electrophoresis. Visualization of the protein spots occurs by staining the gel with silver nitrate, colloidal stains like Coomassie Brilliant Blue or fluorescent dyes. Gels containing different samples are compared by imaging software and differentially expressed protein spots are excised. For identification, proteins are digested (usually by trypsin) and dependent on the type of instrument the peptides can directly be introduced into the mass spectrometer by electrospray ionisation (ESI) or spotted on a target plate for matrix assisted laser desorption ionisation (MALDI) mass spectrometry (see ref. 15 and 16 for details). With the DIGE technology a similar strategy is applied.

(ii) LC-MSMS-mediated proteomics. In contrast to the gel-based approach, this procedure starts with digestion of the protein sample. Peptides are subsequently separated by liquid chromatography (LC). Separated peptides are directly introduced into the mass spectrometer by electrospray ionisation (ESI). An alternative to this on-line LC-MSMS approach is an off-line method where the separated peptides are automatically spotted on a Maldi target plate for subsequent MSMS- identification.

(iii) Antibody array technology. Three formats of this technology are displayed (see ref. 19 and 20 for details). A commonly used method is pre-labelling of the proteins samples, which are subsequently mixed and applied to glass slides pre-spotted with a set of available antibodies. Detection of the captured fluorescent antigens occurs by laser scanning. Second, unlabelled protein samples can be applied to similar antibody slides after which the captured antigens are detected by a cocktail of labelled secondary antibodies matched to the pre-spotted ones. The third method involves spotting of the protein sample antigens on the slide. Subsequent detection occurs by labelled read-out antibodies. 
also detection of post-translational modifications (20). However, current arrays are restricted by the availability of antibodies and cross-reactivity of these. Thus, in contrast to 2-DE and LCMSMS one can only screen for a selected known part of the proteome and as such the present arrays are less useful as discovery tool. However, with the endorsement of the Human Proteome Organisation (HUPO) antibody program in 2004 (29) together with the ability to generate and validate thousands of antibodies per year, it is anticipated that within the near future antibodies will be available for proteins coded by each human gene locus $(30,31)$. Still, the antibody array is limited in detection of proteins that require harsh solubilisation conditions, such as urea and SDS containing buffers, as these can be detrimental for the antibodies.

Next to common proteins captured by all three technologies, each approach allows identification of specific parts of the proteome. Thus, none of them can currently be marked as "golden standard". Due to the complexity of the proteome it is not expected that one total proteome-covering strategy will emerge in the near future. Therefore, researchers should carefully consider their research interest and choose the proper method(s) to investigate their research questions. As such, different proteomics strategies have been applied with respect to adipocyte biology.

\section{Initial proteome studies on adipocyte biology}

Already in 1979 a 2-DE proteome study was conducted on 3T3L1 differentiation (32). Changes in the biosynthesis of 30 cytoplasmic, 9 non-histone chromosome-associated proteins and 24 membrane proteins were found. Unfortunately, only 1 protein could be tentatively identified as actin. Despite that none of the proteins was sequenced, remaining the identity of the proteins unknown, this study demonstrated for the first time that synthesis of several proteins was altered during 3T3-L1 differentiation. Subsequent studies confirmed these results by showing increased $\left[{ }^{3} \mathrm{H}\right]$-leucine incorporation into cellular protein extracts of differentiating 3T3-L1 cells (33) and an increased biosynthesis of glycolytic enzymes in 3T3-F442 cells (34). However, large-scale proteomics studies, including detailed protein identification, on adipocyte biology could only be conducted after the implementation of mass spectrometry in protein research. It lasted until 2001 that the first 2D-maps with identified proteins of mouse adipose tissue were published $(35,36)$.

\section{Proteomics on mouse adipocytes}

Initial proteome studies were conducted on mouse 3T3-L1 cells to discriminate and identify differentially expressed proteins during adipocyte differentiation (37-39). Many proteins were identified that had not been described before in 3T3-L1 cells but, dependent on the experimental conditions, each study revealed a different set of proteins next to commonly identified proteins. This demonstrated the power of proteomics studies but at the same time the sensitivity of the 3T3-L1 cellular proteome for different experimental conditions and the reproducibility limitation of the used 2-DE method. However, a commonly observed effect was the alteration of proteins involved in cytoskeletal re-arrangements, which is an important event during 3T3-L1 differentiation (40-42). Furthermore, a proper functioning and remodelling of the cytoskeletal network is required for insulin signalling and GLUT4 translocation in 3T3-L1 adipocytes (4347). For instance, the actin-based motor protein myosin $5 \mathrm{a}$ is a critical factor for anterograde movement of GLUT4 vesicles along the actin network in 3T3-L1 cells upon insulin-mediated stimulation (43).

Next to cytoskeletal arrangements, proteolytic events play a critical role in the initiation of preadipocyte differentiation (48-50). One proteomics study revealed the protease inhibitor a-2-macroglobulin to be involved in adipocyte differentiation (38). Accumulation of intracellular $\alpha$-2-macroglobulin blocks differentiation while depletion of $\alpha-2$-macroglobulin by polyclonal antibodies again induced a spontaneous differentiation of 3T3-L1 cells. Similar results were found with freshly isolated mouse preadipocytes. Remarkably, the $\alpha$-2-macroglobulin protein found in this study was not mouse-derived. Apparently this protein was taken up from the culture medium that was supplemented with bovine serum. $\alpha$-2-macroglobulin, as protease inhibitor, might regulate this process by proteolysis suppression. Probably, preadipocytes take up this protein to inhibit spontaneous differentiation and upon inactivation of $\alpha$-2-macropglobulin differentiation is initiated.

Our group investigated proteome changes during 3T3-L1 differentiation followed by starvation (39). We identified four categories of proteins: metabolic enzymes, growth regulatory proteins, proteins with functions in cytoskeleton re-arrangements and protein modifiers. Compared to 3T3-L1 differentiation we observed a non-reciprocal regulation of the glycolytic pathway when mature 3T3-L1adipocytes were subjected to caloric restriction. Several other proteins showed a similar behaviour. This indicates that although caloric restriction induces fat release, it results only in a limited pre-adipocyte protein expression pattern. Apparently, once differentiated, adipocytes do not completely return to their preadipocyte status upon caloric restriction. However, when 3T3-L1 adipocytes were subjected to caloric restriction in the presence with TNF- $\alpha$, the protein profile closely resembled the preadipocyte expression pattern. Stimulation of PPAR $\gamma$ inhibits TNF- $\alpha$ effects on mature 3T3-L1 cells (51). Thus, we suggested that TNF- $\alpha$, in addition to caloric 
restriction, stimulates mature 3T3-L1 cells to return further to their preadipocyte status by a forced down-regulation of PPAR $\gamma$.

\section{Organelle proteomics}

Several proteomics studies have been conducted on specific cellular fractions isolated from 3T3-L1 cells, $(52,53)$, mice $(54,55)$ and humans (56). Adipocytes store the triglycerides in lipid droplets but the protein composition of adipocyte lipid droplets remained elusive until identified by mass spectrometry (53). Next to proteins also present on lipid droplets of other mammalian systems such as lipid metabolism enzymes and vesicular traffic controlling proteins, a number of adipocyte-specific ones were determined. Several of these were only identified from basal adipocytes such as 17- $\beta$-hydroxysteroid dehydrogenase type 7 and CGI-49, and others specifically under lipolytic conditions such as adipophilin, caveolin-1, tubulin and lipid-metabolizing enzymes. Presence of some of these proteins on lipid droplets was confirmed by immunofluorescence (53).

Recently, the nuclear proteome of 3T3-L1 cells was investigated during 5 consecutive days of differentiation using a quantitative five-plex SILAC LC-MSMS method (57). With this novel approach differentially expressed proteins could be identified in a temporal fashion. In the nuclear fraction a total of 581 proteins were identified. Among these were e.g. the T-cell transcriptional regulator THO complex 4 that showed highest expression during mid-stage of differentiation and the chromatin modulator SNF2 a that was down-regulated during the start of differentiation and remained at low expression level during the further differentiation. With this novel proteomics approach, this study contributed to a broader understanding of the transcriptional regulation of adipocyte differentiation.

With respect to other organelles, mitochondrial biogenesis and remodelling during 3T3-L1 differentiation was discovered as a novel property of adipocytes (52). When the same experiment was repeated in the presence of the insulin sensitizing thiazolidinedione (TZD) drug rosiglitazone, again mitochondrial biosynthesis was observed. This was accompanied by increased expression of several mitochondrial proteins involved in fatty acid oxidation in the 3T3-L1 cells (52) as well as in the ob/ob mice (54). The correlation between the expression levels of the identified proteins and their corresponding mRNA's was low, which implied a regulation of the mitochondrial proteins at the post-translational level.

\section{Effects of TZD's on the 3T3-L1 proteome}

The insulin sensitizers TZD's require adipose tissue for their therapeutic actions (58-60) although they stimulate fat cell differentiation, a known risk factor for insulin resistance. To in- vestigate this paradoxical issue we examined the effect of two TZD's (pioglitazone and rosiglitazone) on the proteome of crude cell lysates of 3T3-L1 cells. We observed a pioglitazone- and rosiglitazone-mediated triglyceride accumulation during 3T3L1 differentiation and induction of proteins involved in intracellular fatty acid transport, glycerol-3-phosphate synthesis and gluconeogenesis from non-carbohydrate substrates. At the same time, both TZD's induced tricaboxylic acid cycle proteins, the complete fatty acid beta-oxidation pathway and oxidative phosphorylation proteins. Thus, concomitant with increased triglyceride storage the TZD's also increased fatty acid catabolism (61). In a parallel study the effect of rosiglitazone on mature 3T3-L1 adipocytes was investigated with a combined transcriptomics and proteomics study (62). Decreased lipid contents were observed together with a mRNA and protein expression pattern that indicated a switch in metabolism towards lipid catabolism. Furthermore, rosiglitazone reduced adipokine expression both on mRNA and protein level, except for the insulin sensitizer adiponectin and apolipoprotein $\mathrm{E}$ (ApoE). Together, these proteomics results added new information to support the view that TZD's exert their therapeutic effects through the fatty acid storage and catabolism capacity of the adipose tissue (63) and through a change in the adipokine profile.

\section{Proteomics on human adipocytes}

Despite its value for obesity research the 3T3-L1 model is hampered by its murine nature. A comparison of studies conducted on murine and human adipocytes increasingly showed differences between the two model systems regarding adipogenesis and adipokine secretion (64-67). The value of mouse models to recapitulate human obesity is thus questionable. Detailed comparative proteome studies may reveal how well the mouse model is suited, at least on the proteome level, as a model for human obesity studies. Recently, an in-depth proteome analysis of 3T3L1 adipocytes was published (68) using subcellular fractionation and high sensitive protein identification by sophisticated mass spectrometry. This strategy revealed 3,287 identified proteins and is currently the largest high confidence proteome map on adipocyte biology. A similar study with subcutaneous and visceral human adipocytes is still awaited but would allow a detailed comparison between the two species but also between the different human fat depots, which enables extensive functional characterization of the adipogenic process.

Proteome studies on human adipogenesis have been conducted with human adult stem cells derived from liposuction aspirates (69) and with mesenchymal stem cells (70,71). The human adult stem cells revealed a relative high percentage $(>40 \%)$ of identical proteins compared to mouse adipose tissue and 3T3- 
L1 cells. In addition, the functional properties of all identified proteins, e.g. cytoskeletal rearrangements, metabolic and redox enzymes and protein processing, were highly similar compared to proteins earlier identified from murine models. These results might be explained by the applied 2-DE method that primarily reveals the high abundant proteins. (Subtle) differences that distinguish human adipocytes from murine adipocytes require indepth investigation of the proteomes on a larger scale. Ideally this is done by subcellular fractionation of the adipose material and analysis with more sensitive methods like wide-range 2-DE and quantitative LC-MSMS.

Primary human adipocytes can be isolated from fresh adipose tissue but the propagation and manipulation possibilities of these cells are limited which make them less easy to use. Recently, adipose tissue explants have been used $(72,73)$ in proteome studies but these contain next to adipocytes also stromal vascular cells, which make it difficult to determine the origin of the identified proteins. Furthermore, the tissue explants themselves do not allow the examination of the adipocyte differentiation process.

Immortalized human preadipocytes appear a promising model system $(74,75)$ and developments in this field are ongoing. Other interesting cells are preadipocytes derived from a Simpson-Golabi-Behmel syndrome (SGBS) patient (76). SGBS cells can be propagated for at least 30 generations without loosing their differentiation capacity. Differentiated SGBS cells are similar to human subcutaneous adipocytes with respect to morphology and biochemical characteristics but are easier to manipulate and therefore ideal to work with. Currently, the SGBS cells form an important in vitro model in the field of adipocyte biology research.

\section{Analysis of adipokine secretion by proteomics}

Adipokines play an important role in normal physiology (77), however, disturbances in adipokine profiles coinciding the development of obesity are associated with the onset of metabolic complications (78-82). Proteomics research has had a major impact on the identification of novel adipokines. Started with 3T3L1 cells, different proteomic approaches have been applied to investigate the change in adipokine profiles during differentiation. Kratchmarova et al (83) found 20 different secreted proteins by one-dimensional electrophoresis and LC-MSMS. Wang et al (84) identified 41 different proteins by a combination of 2-DE and mass spectrometry. Together, both studies revealed several different proteins that had not been associated before with adipocyte secretion. More importantly, these studies showed for the first time the applicability of proteomics technology on another level of adipocyte biology, that is adipokine expression profiling.

\section{Adipocyte secretion routes}

Proteins bearing a $\mathrm{N}$-terminal secretion signal peptide are secreted via the ER-Golgi pathway. However, next to this so-called classical pathway at least 3 additional routes of protein secretion are present in eukaryotic cells $(85,86)$. In a study on adipokine profiles from rat adipose cells 99 proteins out of 183 identified were considered as non-secreted because they lacked a secretion signal peptide (87). However, structural analysis of proteins for signal secretion peptides might lead to an under-representation of adipocyte-derived proteins present in the extracellular space. Our group used a blocking strategy to discriminate between truly secreted proteins and proteins derived from cell leakage (84). This method provided important information about the secretory properties of the identified proteins. For instance, cyclophilin A, which is known to be secreted from vascular smooth muscle cells (88), was identified as a truly adipocyte-secreted protein while the structure of this protein does not indicate secretory motives (84).

We showed that adipocyte secretion is stimulated by insulin but not on the transcriptional level of the secreted proteins. Instead, insulin promoted the transcription of post-translational processing proteins, particularly those that are involved in proteolysis (12). The regulation of processing enzymes can increase protein secretion by shedding of transmembrane proteins, a process termed ectocytosis. This process is another way to bring secretory proteins without secretion motives into the extracellular space $(89,90)$. For example, matrix metalloproteinases (MMP's) are involved in this phenomenon and several subtypes of these proteins have been identified as secreted proteins from adipocytes $(12,84,87)$. Whether these proteins are actively involved in proteolysis of adipocyte-bearing transmembrane proteins and as such stimulate adipokine secretion remains elusive.

Another route for protein secretion by adipocytes is the release of microvesicles. A proteome analysis of microvesicles derived form 3T3-L1 cells revealed many proteins previously identified as adipokine (91). Microvesicles can derive from direct budding from the plasma membrane (92) or from exocytosis of endosome-derived multivesicular bodies known as exosomes (93). Both type of vehicles can be released in the intracellular space and are also found in body fluids. They function in the transfer of proteins and RNA molecules between cells. Furthermore, microvesicles appear to specifically target recipient cells (reviewed in 92,93). With respect to adipokines, this mechanism may function as a targeted communication pathway between the adipose tissue and other tissues like muscle, liver and intestine. In-depth proteome studies of adipocyte-derived microvesicles (94) will be necessary to further understand their functional properties, how they target their recipient cells and how they are related to obesity-related disorders. 


\section{Human adipokines identified by proteomics}

In the human body the visceral and subcutaneous fat depots are important sources for adipokines present in the circulation. Especially the accumulation of visceral fat and the related increased free fatty acid flux together with a deregulation of visceral adipokine profiles are associated with insulin resistance, endothelial dysfunction and a pro-inflammatory state $(80,95)$. So far, several studies appeared on profiling of human adipokines, each applying a different experimental approach $(71-73,96,97)$. One study investigated mammary fat and its interstitial fluid by a combination of 2-DE, mass spectrometry and antibody array techniques (97). 359 different proteins were identified, with functions in signal transduction, energy metabolism, cellular communication, cell growth and maintenance, and immune response. Although the relation between mammary fat and metabolic disturbances such as insulin resistance is less clear, obese woman are considered to be on a higher risk for developing post-menopausal breast cancer (98). Mammary adiposederived factors may be involved in this process as they are able to stimulate tumor cell growth.

So far, three studies appeared on adipokine profiles from freshly isolated human subcutaneous and visceral adipose tissue $(72,73,96)$. Secretomes of adipose tissue explants were examined by SDS-PAGE-LC-MSMS (72) and by antibody arrays (73), respectively. The visceral adipose tissue revealed 259 identified proteins from which 108 contained a secretion signal peptide. This left 151 proteins to be secreted via a non-classical pathway or even non-secreted. Indeed, the tissue explants appeared to contain some residual serum and intracellular proteins (72). The secretome from subcutaneous fat was investigated by an array containing antibodies against 120 different cytokines. Sixteen proteins were identified from which 5 were regulated by PPAR agonists (73).

Despite the high significance to investigate human adipokine expression, the above two studies could not discriminate the origin of their identified proteins. As adipose tissue explants mainly consist of adipocytes and stromal vascular cells it remains elusive from which cells the secreted proteins are derived. To resolve questions about adipose tissue-derived proteins in the circulation this is a less severe problem. However, to dissect communication between adipocytes and other cell types this method is less useful. For instance, the question how macrophages are recruited into adipose tissue of obese persons is best studied by using pure cell cultures as secreted factors from differentiated adipocytes showed monocyte chemotactic activities (99).

Secretion profiles from undifferentiated and differentiated primary cultures of human adipose-derived stem cells revealed 81 differentially expressed proteins as identified by a $2-\mathrm{DE}$ ap- proach (96). About $72 \%$ of these proteins had already been discovered in previous proteomics studies showing a considerable overlap between rodent and human adipokine profiles. Since this study was conducted with 2-DE, the more subtle differences between the two species remain to be discovered. However, HSP47 (SERPINH1) a serpin family member, was identified as a new human adipocyte-secreted protein.

\section{Adipocyte extracellular matrix}

Extracellular matrix (ECM) proteins constitute a major part of the adipocyte secretion profile known today $(12,72,83,84,96)$. Remodelling of the ECM plays an important role in adipocyte differentiation $(100,101)$ and particularly MMP have been demonstrated to be involved in this process in vitro $(102,103)$ and in vivo $(104,105)$. Previously, we determined a differential expression of several ECM proteins from mature 3T3-L1 cells by a novel stable isotope labelling method (106). Based on these results it was concluded that ECM remodelling is also a functional property of mature 3T3-L1 adipocytes.

Recently it was shown that the ECM of human preadipocytes could be modulated by macrophage-secreted factors and that interstitial fibrosis in obese white adipose tissue coincides with infiltration of inflammatory cells $(107,108)$. This may imply that adipocyte-ECM modulation is associated with the inflammatory state found in the adipose tissue of obese subjects and may be linked to metabolic deregulation. A study by Khan et al (109) demonstrated that the absence of the adipocyte ECM protein collagen VI resulted in an improvement of whole body energy homeostasis of $o b / o b$ mice together with enlarged adipocyte size. This paradoxal finding was explained by a weakening of the ECM allowing increased triglyceride storage. As such, excess adipose tissue ECM formation during obesity may prevent storage of fat during excess energy intake and may induce plasma glucose and free fatty acid levels.

Together, the adipocyte ECM appears to play an important role in adipose tissue biology. However, the composition of the adipocyte ECM and how it is changed under different inflammatory and nutrient conditions is currently unclear.

\section{Proteomics on human adipose tissue biopsies}

So far, a limited number of proteome analyses have been conducted on human subcutaneous and visceral adipose tissue biopsies. These were from low and high-fat oxidizing obese subjects (110), polycystic ovary syndrome subjects (111) and non-diabetic obese subjects (112). All three studies were performed with a 2-DE approach. Claessens et al (110) used a subtraction method to discriminate truly adipocyte proteins from contaminating blood-derived proteins and observed an induc- 
tion of methylmalonate-semialdehyde dehydrogenase in low-fat oxidizing subjects. This may account for an increased valine catabolism as compensatory mechanism for reduced carbohydrate metabolism.

Upregulation of endoplasmic reticulum stress-related proteins was observed in fat biopsies from non-diabetic obese subjects compared to lean ones (112). Although these proteins are involved in an unfolded protein response, most of these have also been assigned generally stress-related proteins (24). The same is true for the proteins identified by Corton et al (111). Together, these studies provided initial insight in proteome changes in adipose tissue from human subjects. In-depth proteome analyses may provide a further understanding of the biology of the adipose tissue with respect to obesity and obesity-related disorders. However, this requires complexity-reducing sample preparation and more sensitive analysis methods.

\section{Conclusion and future directions}

Since 2001 proteomics research on adipose biology has evolved and many proteins that had not been associated with adipocytes before have been identified. In addition, by means of proteomics data several novel biological features of adipocytes have been discovered. As indicated, none of the existing proteomics strategies can cover entire proteomes of mammalian systems at once. Thus the coverage of the total proteome of (pre)adipocytes and proteome changes during preadipocyte differentiation requires a combination of current analysis techniques. Subcellular fractionation, wide-scale 2-DE, high sensitive mass spectrometry and high-density antibody arrays will all contribute to a further understanding of adipocyte biology.

Future applications for proteomics research in adipose biology are the further dissection of $(i)$ the molecular events during human adipogenesis, (ii) the remodelling of the adipocyte ECM, and (iii) the link between obesity and obesity-related metabolic complications. Adipocyte-secreted adipokines are supposed to play an important role in obesity-related disorders. However, how the change in adipokine profiles influence neighbour and remote target cells and how they induce metabolic complications remains elusive. A challenging task for proteomics researchers lies ahead.

\section{References}

1. Rosen ED, Spiegelman BM. Adipocytes as regulators of energy balance and glucose homeostasis. Nature 2006; 444: 847-853.

2. Trayhurn P. Endocrine and signalling role of adipose tissue: new perspectives on fat. Acta Physiol Scand 2005; 184: 285-293.

3. Bluher M. Adipose tissue dysfunction in obesity. Exp Clin Endocrinol Diabetes 2009; 117: 241-250.
4. Goossens GH. The role of adipose tissue dysfunction in the pathogenesis of obesity-related insulin resistance. Physiol Behav 2008; 94: 206-218.

5. Haslam D. Obesity: a medical history. Obes Rev 2007; 8 Suppl 1:31-36.

6. Haslam D, Sattar N, Lean M. ABC of obesity. Obesity - time to wake up. BMJ 2006; 333: 640-642.

7. Haslam DW, James WP. Obesity. Lancet 2005; 366: 11971209.

8. Guan HP, Li Y, Jensen MV, Newgard CB, Steppan CM, Lazar MA. A futile metabolic cycle activated in adipocytes by antidiabetic agents. Nat Med 2002; 8: 1122-1128.

9. Burton GR, Guan Y, Nagarajan R, McGehee RE, Jr. Microarray analysis of gene expression during early adipocyte differentiation. Gene 2002; 293: 21-31.

10. Soukas A, Socci ND, Saatkamp BD, Novelli S, Friedman JM. Distinct transcriptional profiles of adipogenesis in vivo and in vitro. J Biol Chem 2001; 276: 34167-34174.

11. Pradet-Balade B, Boulme F, Beug H, Mullner EW, Garcia-Sanz JA. Translation control: bridging the gap between genomics and proteomics? Trends Biochem Sci 2001; 26: 225-229.

12. Wang P, Keijer J, Bunschoten A, Bouwman F, Renes J, Mariman E. Insulin modulates the secretion of proteins from mature 3T3-L1 adipocytes: a role for transcriptional regulation of processing. Diabetologia 2006; 49: 2453-2462.

13. Tyers M, Mann M. From genomics to proteomics. Nature 2003; 422: 193-197.

14. Sharan R, Ulitsky I, Shamir R. Network-based prediction of protein function. Mol Syst Biol 2007; 3: 88.

15. Gorg A, Drews O, Luck C, Weiland F, Weiss W. 2-DE with IPGs. Electrophoresis 2009; 30 (Suppl 1): S122-132.

16. Rabilloud T. Two-dimensional gel electrophoresis in proteomics: old, old fashioned, but it still climbs up the mountains. Proteomics 2002; 2: 3-10.

17. Chen G, Pramanik BN. Application of LC/MS to proteomics studies: current status and future prospects. Drug Discov Today 2009; 14: 465-471.

18. Domon B, Aebersold R. Mass spectrometry and protein analysis. Science 2006; 312: 212-217.

19. Wingren C, Borrebaeck CA. Antibody-based microarrays. Methods Mol Biol 2009; 509: 57-84.

20. Kingsmore SF. Multiplexed protein measurement: technologies and applications of protein and antibody arrays. Nat Rev Drug Discov 2006; 5: 310-320.

21. Fichmann J, Westermeier R. 2-D protein gel electrophoresis. An overview. Methods Mol Biol 1999; 112: 1-7.

22. Marouga R, David S, Hawkins E. The development of the DIGE system: 2D fluorescence difference gel analysis tech- 
nology. Anal Bioanal Chem 2005; 382: 669-678.

23. Gade D, Thiermann J, Markowsky D, Rabus R. Evaluation of two-dimensional difference gel electrophoresis for protein profiling. Soluble proteins of the marine bacterium Pirellula sp. strain 1. J Mol Microbiol Biotechnol 2003; 5: 240-251.

24. Wang P, Bouwman FG, Mariman EC. Generally detected proteins in comparative proteomics - a matter of cellular stress response? Proteomics 2009; 9: 2955-2966.

25. Heck AJ, Krijgsveld J. Mass spectrometry-based quantitative proteomics. Expert Rev Proteomics 2004; 1: 317-326.

26. Ong SE, Mann M. Mass spectrometry-based proteomics turns quantitative. Nat Chem Biol 2005; 1: 252-262.

27. Yates JR, 3rd. Mass spectral analysis in proteomics. Annu Rev Biophys Biomol Struct 2004; 33: 297-316.

28. Aebersold R, Mann M. Mass spectrometry-based proteomics. Nature 2003; 422: 198-207.

29. Nilsson P, Paavilainen L, Larsson K, Odling J, Sundberg M, Andersson AC, et al. Towards a human proteome atlas: high-throughput generation of mono-specific antibodies for tissue profiling. Proteomics 2005; 5: 4327-4337.

30. Tegel H, Steen J, Konrad A, Nikdin H, Pettersson K, Stenvall $\mathrm{M}$, et al. High-throughput protein production - lessons from scaling up from 10 to 288 recombinant proteins per week. Biotechnol J 2009; 4: 51-57.

31. Ponten F, Jirstrom K, Uhlen M. The Human Protein Atlas - a tool for pathology. J Pathol 2008; 216: 387-393.

32. Sidhu RS. Two-dimensional electrophoretic analyses of proteins synthesized during differentiation of 3T3-L1 preadipocytes. J Biol Chem 1979; 254: 11111-11118.

33. Student AK, Hsu RY, Lane MD. Induction of fatty acid synthetase synthesis in differentiating 3T3-L1 preadipocytes. $J$ Biol Chem 1980; 255: 4745-4750.

34. Spiegelman BM, Green H. Control of specific protein biosynthesis during the adipose conversion of 3T3 cells. J Biol Chem 1980; 255: 8811-8818.

35. Lanne B, Potthast F, Hoglund A, Brockenhuus von Lowenhielm H, Nystrom AC, Nilsson F, et al. Thiourea enhances mapping of the proteome from murine white adipose tissue. Proteomics 2001; 1: 819-828.

36. Sanchez JC, Chiappe D, Converset V, Hoogland C, Binz PA, Paesano S, et al. The mouse SWISS-2D PAGE database: a tool for proteomics study of diabetes and obesity. Proteomics 2001; 1: 136-163.

37. Welsh GI, Griffiths MR, Webster KJ, Page MJ, Tavare JM. Proteome analysis of adipogenesis. Proteomics 2004; 4: 1042-1051.

38. Choi KL, Wang Y, Tse CA, Lam KS, Cooper GJ, Xu A. Proteomic analysis of adipocyte differentiation: Evidence that alpha2 macroglobulin is involved in the adipose conversion of 3T3 L1 preadipocytes. Proteomics 2004; 4: 1840-1848.

39. Renes J, Bouwman F, Noben JP, Evelo C, Robben J, Mariman E. Protein profiling of 3T3-L1 adipocyte differentiation and (tumor necrosis factor alpha-mediated) starvation. Cell Mol Life Sci 2005; 62: 492-503.

40. Kawaguchi N, Sundberg C, Kveiborg M, Moghadaszadeh B, Asmar M, Dietrich N, et al. ADAM12 induces actin cytoskeleton and extracellular matrix reorganization during early adipocyte differentiation by regulating betal integrin function. J Cell Sci 2003; 116: 3893-3904.

41. Lieber JG, Evans RM. Disruption of the vimentin intermediate filament system during adipose conversion of 3T3-L1 cells inhibits lipid droplet accumulation. J Cell Sci 1996; 109 (Pt 13): 3047-3058.

42. Rodriguez Fernandez JL, Ben-Ze'ev A. Regulation of fibronectin, integrin and cytoskeleton expression in differentiating adipocytes: inhibition by extracellular matrix and polylysine. Differentiation 1989; 42: 65-74.

43. Yoshizaki T, Imamura T, Babendure JL, Lu JC, Sonoda N, Olefsky JM. Myosin 5a is an insulin-stimulated Akt2 (protein kinase Bbeta) substrate modulating GLUT4 vesicle translocation. Mol Cell Biol 2007; 27: 5172-5183.

44. Huang J, Imamura T, Babendure JL, Lu JC, Olefsky JM. Disruption of microtubules ablates the specificity of insulin signaling to GLUT4 translocation in 3T3-L1 adipocytes. J Biol Chem 2005; 280: 42300-42306.

45. Olson AL, Eyster CA, Duggins QS, Knight JB. Insulin promotes formation of polymerized microtubules by a phosphatidylinositol 3-kinase-independent, actin-dependent pathway in 3T3-L1 adipocytes. Endocrinology 2003; 144: 5030-5039.

46. Kanzaki M, Pessin JE. Insulin-stimulated GLUT4 translocation in adipocytes is dependent upon cortical actin remodeling. J Biol Chem 2001; 276: 42436-42444.

47. Guilherme A, Emoto M, Buxton JM, Bose S, Sabini R, Theurkauf WE, et al. Perinuclear localization and insulin responsiveness of GLUT4 requires cytoskeletal integrity in 3T3-L1 adipocytes. J Biol Chem 2000; 275: 38151-38159.

48. Alexander CM, Selvarajan S, Mudgett J, Werb Z. Stromelysin-1 regulates adipogenesis during mammary gland involution. J Cell Biol 2001; 152: 693-703.

49. Crandall DL, Busler DE, McHendry-Rinde B, Groeling TM, Kral JG. Autocrine regulation of human preadipocyte migration by plasminogen activator inhibitor-1. J Clin Endocrinol Metab 2000; 85: 2609-2614.

50. Patel YM, Lane MD. Role of calpain in adipocyte differentiation. Proc Natl Acad Sci USA 1999; 96: 1279-1284. 
51. Souza SC, Yamamoto MT, Franciosa MD, Lien P, Greenberg AS. BRL 49653 blocks the lipolytic actions of tumor necrosis factor-alpha: a potential new insulin-sensitizing mechanism for thiazolidinediones. Diabetes 1998; 47: 691-695.

52. Wilson-Fritch L, Burkart A, Bell G, Mendelson K, Leszyk J, Nicoloro S, et al. Mitochondrial biogenesis and remodeling during adipogenesis and in response to the insulin sensitizer rosiglitazone. Mol Cell Biol 2003; 23: 1085-1094.

53. Brasaemle DL, Dolios G, Shapiro L, Wang R. Proteomic analysis of proteins associated with lipid droplets of basal and lipolytically stimulated 3T3-L1 adipocytes. J Biol Chem 2004; 279: 46835-46842.

54. Wilson-Fritch L, Nicoloro S, Chouinard M, Lazar MA, Chui PC, Leszyk J, et al. Mitochondrial remodeling in adipose tissue associated with obesity and treatment with rosiglitazone. J Clin Invest 2004; 114: 1281-1289.

55. Bluher M, Wilson-Fritch L, Leszyk J, Laustsen PG, Corvera S, Kahn CR. Role of insulin action and cell size on protein expression patterns in adipocytes. J Biol Chem 2004; 279: 31902-31909.

56. Aboulaich N, Vainonen JP, Stralfors P, Vener AV. Vectorial proteomics reveal targeting, phosphorylation and specific fragmentation of polymerase I and transcript release factor (PTRF) at the surface of caveolae in human adipocytes. Biochem J 2004; 383: 237-248.

57. Molina H, Yang Y, Ruch T, Kim JW, Mortensen P, Otto T, et al. Temporal profiling of the adipocyte proteome during differentiation using a five-plex SILAC based strategy. J Proteome Res 2009; 8: 48-58.

58. Hallakou S, Doare L, Foufelle F, Kergoat M, Guerre-Millo $\mathrm{M}$, Berthault MF, et al. Pioglitazone induces in vivo adipocyte differentiation in the obese Zucker fa/fa rat. Diabetes 1997; 46: 1393-1399.

59. de Souza CJ, Eckhardt M, Gagen K, Dong M, Chen W, Laurent D, et al. Effects of pioglitazone on adipose tissue remodeling within the setting of obesity and insulin resistance. Diabetes 2001; 50: 1863-1871.

60. Oakes ND, Thalen PG, Jacinto SM, Ljung B. Thiazolidinediones increase plasma-adipose tissue FFA exchange capacity and enhance insulin-mediated control of systemic FFA availability. Diabetes 2001; 50: 1158-1165.

61. Renes J, van Tilburg J, van Haaften R, Bouwman F, Kodde A, Evelo C, et al. Thiazolidinediones regulate expression of proteins involved in triacylglyceride storage and fatty acid oxidation in 3T3-L1 (pre-)adipocytes. Adipocytes 2006; 2 : 75-91.

62. Wang P, Renes J, Bouwman F, Bunschoten A, Mariman E, Keijer J. Absence of an adipogenic effect of rosiglitazone on mature 3T3-L1 adipocytes: increase of lipid catabolism and reduction of adipokine expression. Diabetologia 2007; 50: 654-665.

63. Yki-Jarvinen H. Thiazolidinediones. N Engl J Med 2004; 351: 1106-1118.

64. Steppan CM, Bailey ST, Bhat S, Brown EJ, Banerjee RR, Wright CM, et al. The hormone resistin links obesity to diabetes. Nature 2001; 409: 307-312.

65. Smith SR, Gawronska-Kozak B, Janderova L, Nguyen T, Murrell A, Stephens JM, et al. Agouti expression in human adipose tissue: functional consequences and increased expression in type 2 diabetes. Diabetes 2003; 52: 2914-2922.

66. Heilbronn LK, Rood J, Janderova L, Albu JB, Kelley DE, Ravussin E, et al. Relationship between serum resistin concentrations and insulin resistance in nonobese, obese, and obese diabetic subjects. J Clin Endocrinol Metab 2004; 89: 1844-1848.

67. Arner P. Resistin: yet another adipokine tells us that men are not mice. Diabetologia 2005; 48: 2203-2205.

68. Adachi J, Kumar C, Zhang Y, Mann M. In-depth analysis of the adipocyte proteome by mass spectrometry and bioinformatics. Mol Cell Proteomics 2007; 6: 1257-1273.

69. DeLany JP, Floyd ZE, Zvonic S, Smith A, Gravois A, Reiners $\mathrm{E}$, et al. Proteomic analysis of primary cultures of human adipose-derived stem cells: modulation by adipogenesis. Mol Cell Proteomics 2005; 4: 731-740.

70. Lee HK, Lee BH, Park SA, Kim CW. The proteomic analysis of an adipocyte differentiated from human mesenchymal stem cells using two-dimensional gel electrophoresis. Proteomics 2006; 6: 1223-1229.

71. Chiellini C, Cochet O, Negroni L, Samson M, Poggi M, Ailhaud G, et al. Characterization of human mesenchymal stem cell secretome at early steps of adipocyte and osteoblast differentiation. BMC Mol Biol 2008; 9: 26.

72. Alvarez-Llamas G, Szalowska E, de Vries MP, Weening D, Landman K, Hoek A, et al. Characterization of the human visceral adipose tissue secretome. Mol Cell Proteomics 2007; 6: 589-600.

73. Klimcakova E, Moro C, Mazzucotelli A, Lolmede K, Viguerie N, Galitzky J, et al. Profiling of adipokines secreted from human subcutaneous adipose tissue in response to PPAR agonists. Biochem Biophys Res Commun 2007; 358: 897-902.

74. Rodriguez AM, Elabd C, Delteil F, Astier J, Vernochet C, Saint-Marc P, et al. Adipocyte differentiation of multipotent cells established from human adipose tissue. Biochem Biophys Res Commun 2004; 315: 255-263.

75. Darimont C, Mace K. Immortalization of human preadipocytes. Biochimie 2003; 85: 1231-1233. 
76. Wabitsch M, Brenner RE, Melzner I, Braun M, Moller P, Heinze E, et al. Characterization of a human preadipocyte cell strain with high capacity for adipose differentiation. Int J Obes Relat Metab Disord 2001; 25: 8-15.

77. Wang P, Mariman E, Renes J, Keijer J. The secretory function of adipocytes in the physiology of white adipose tissue. J Cell Physiol 2008; 216: 3-13.

78. Trayhurn P, Wang B, Wood IS. Hypoxia in adipose tissue: a basis for the dysregulation of tissue function in obesity? $\mathrm{Br} J$ Nutr 2008; 100: 227-235.

79. Trayhurn P, Bing C, Wood IS. Adipose tissue and adipokines - energy regulation from the human perspective. J Nutr 2006; 136: 1935S-1939S.

80. Ritchie SA, Connell JM. The link between abdominal obesity, metabolic syndrome and cardiovascular disease. Nutr Metab Cardiovasc Dis 2007; 17: 319-326.

81. Trayhurn P. Adipocyte biology. Obes Rev 2007; 8 (Suppl 1): 41-44.

82. Antuna-Puente B, Feve B, Fellahi S, Bastard JP. Adipokines: the missing link between insulin resistance and obesity. Diabetes Metab 2008; 34: 2-11.

83. Kratchmarova I, Kalume DE, Blagoev B, Scherer PE, Podtelejnikov AV, Molina $\mathrm{H}$, et al. A proteomic approach for identification of secreted proteins during the differentiation of 3T3-L1 preadipocytes to adipocytes. Mol Cell Proteomics 2002; 1: 213-222.

84. Wang P, Mariman E, Keijer J, Bouwman F, Noben JP, Robben J, et al. Profiling of the secreted proteins during 3T3-L1 adipocyte differentiation leads to the identification of novel adipokines. Cell Mol Life Sci 2004; 61: 2405-2417.

85. Nickel W, Rabouille C. Mechanisms of regulated unconventional protein secretion. Nat Rev Mol Cell Biol 2009; 10: 148155.

86. Nickel W. The mystery of nonclassical protein secretion. A current view on cargo proteins and potential export routes. Eur J Biochem 2003; 270: 2109-2119.

87. Chen X, Cushman SW, Pannell LK, Hess S. Quantitative proteomic analysis of the secretory proteins from rat adipose cells using a 2D liquid chromatography-MS/MS approach. J Proteome Res 2005; 4: 570-577.

88. Jin ZG, Melaragno MG, Liao DF, Yan C, Haendeler J, Suh YA, et al. Cyclophilin A is a secreted growth factor induced by oxidative stress. Circ Res 2000; 87: 789-796.

89. Huovila AP, Turner AJ, Pelto-Huikko M, Karkkainen I, Ortiz RM. Shedding light on ADAM metalloproteinases. Trends Biochem Sci 2005; 30: 413-422.

90. Mullberg J, Althoff K, Jostock T, Rose-John S. The importance of shedding of membrane proteins for cytokine biol- ogy. Eur Cytokine Netw 2000; 11: 27-38.

91. Aoki N, Jin-no S, Nakagawa Y, Asai N, Arakawa E, Tamura $\mathrm{N}$, et al. Identification and characterization of microvesicles secreted by 3T3-L1 adipocytes: redox- and hormonedependent induction of milk fat globule-epidermal growth factor 8-associated microvesicles. Endocrinology 2007; 148: 3850-3862.

92. Cocucci E, Racchetti G, Meldolesi J. Shedding microvesicles: artefacts no more. Trends Cell Biol 2009; 19: 43-51.

93. Simons M, Raposo G. Exosomes - vesicular carriers for intercellular communication. Curr Opin Cell Biol 2009.

94. Xiao Z, Blonder J, Zhou M, Veenstra TD. Proteomic analysis of extracellular matrix and vesicles. J Proteomics 2009; 72: 34-45.

95. Rodriguez A, Catalan V, Gomez-Ambrosi J, Fruhbeck G. Visceral and subcutaneous adiposity: are both potential therapeutic targets for tackling the metabolic syndrome? Curr Pharm Des 2007; 13: 2169-2175.

96. Zvonic S, Lefevre M, Kilroy G, Floyd ZE, DeLany JP, Kheterpal I, et al. Secretome of primary cultures of human adipose-derived stem cells: modulation of serpins by adipogenesis. Mol Cell Proteomics 2007; 6: 18-28.

97. Celis JE, Moreira JM, Cabezon T, Gromov P, Friis E, Rank $\mathrm{F}$, et al. Identification of extracellular and intracellular signaling components of the mammary adipose tissue and its interstitial fluid in high risk breast cancer patients: toward dissecting the molecular circuitry of epithelial-adipocyte stromal cell interactions. Mol Cell Proteomics 2005; 4: 492522.

98. Harvie M, Hooper L, Howell AH. Central obesity and breast cancer risk: a systematic review. Obes Rev 2003; 4: 157-173.

99. Han CY, Subramanian S, Chan CK, Omer M, Chiba T, Wight TN, et al. Adipocyte-derived serum amyloid A3 and hyaluronan play a role in monocyte recruitment and adhesion. Diabetes 2007; 56: 2260-2273.

100. Kubo Y, Kaidzu S, Nakajima I, Takenouchi K, Nakamura F. Organization of extracellular matrix components during differentiation of adipocytes in long-term culture. In Vitro Cell Dev Biol Anim 2000; 36: 38-44.

101. Antras J, Hilliou F, Redziniak G, Pairault J. Decreased biosynthesis of actin and cellular fibronectin during adipose conversion of 3T3-F442A cells. Reorganization of the cytoarchitecture and extracellular matrix fibronectin. Biol Cell 1989; 66: 247-254.

102. Croissandeau G, Chretien M, Mbikay M. Involvement of matrix metalloproteinases in the adipose conversion of 3T3-L1 preadipocytes. Biochem J 2002; 364: 739-746. 
103. Bouloumie A, Sengenes C, Portolan G, Galitzky J, Lafon$\tan$ M. Adipocyte produces matrix metalloproteinases 2 and 9: involvement in adipose differentiation. Diabetes 2001; 50: 2080-2086.

104. Chun TH, Hotary KB, Sabeh F, Saltiel AR, Allen ED, Weiss SJ. A pericellular collagenase directs the 3-dimensional development of white adipose tissue. Cell 2006; 125: 577-591.

105. Chavey C, Mari B, Monthouel MN, Bonnafous S, Anglard $\mathrm{P}$, Van Obberghen E, et al. Matrix metalloproteinases are differentially expressed in adipose tissue during obesity and modulate adipocyte differentiation. J Biol Chem 2003; 278: 11888-11896.

106. Bouwman F, Renes J, Mariman E. A combination of protein profiling and isotopomer analysis using matrix-assisted laser desorption/ionization-time of flight mass spectrometry reveals an active metabolism of the extracellular matrix of 3T3-L1 adipocytes. Proteomics 2004; 4: 3855-3863.

107. Keophiphath M, Achard V, Henegar C, Rouault C, Clement K, Lacasa D. Macrophage-secreted factors promote a profibrotic phenotype in human preadipocytes. Mol Endocrinol 2009; 23: 11-24.

108. Henegar C, Tordjman J, Achard V, Lacasa D, Cremer I,
Guerre-Millo M, et al. Adipose tissue transcriptomic signature highlights the pathological relevance of extracellular matrix in human obesity. Genome Biol 2008; 9: R14.

109. Khan T, Muise ES, Iyengar P, Wang ZV, Chandalia M, Abate N, et al. Metabolic dysregulation and adipose tissue fibrosis: role of collagen VI. Mol Cell Biol 2009; 29: 1575-1591.

110. Claessens M, Saris W, Bouwman F, Evelo C, Hul G, Blaak $\mathrm{E}$, et al. Differential valine metabolism in adipose tissue of low and high fat-oxidizing obese subjects. Proteomics Clin. Appli. 2007; 1: 1306-1315.

111. Corton M, Botella-Carretero JI, Lopez JA, Camafeita E, San Millan JL, Escobar-Morreale HF, et al. Proteomic analysis of human omental adipose tissue in the polycystic ovary syndrome using two-dimensional difference gel electrophoresis and mass spectrometry. Hum Reprod 2008; 23: 651-661.

112. Boden G, Duan X, Homko C, Molina EJ, Song W, Perez O, et al. Increase in endoplasmic reticulum stress-related proteins and genes in adipose tissue of obese, insulin-resistant individuals. Diabetes 2008; 57: 2438-2444. 